\title{
Methyl jasmonate mediates melatonin-induced cold tolerance of grafted watermelon plants
}

\author{
Hao Li', Yanliang Guo', Zhixiang Lan', Kai Xu', Jingjing Chang', Golam Jalal Ahammed², Jianxiang Ma', \\ Chunhua Wei ${ }^{1}$ and Xian Zhang $\mathbb{B}^{1,3}$
}

\begin{abstract}
Root-shoot communication has a critical role in plant adaptation to environmental stress. Grafting is widely applied to enhance the abiotic stress tolerance of many horticultural crop species; however, the signal transduction mechanism involved in this tolerance remains unknown. Here, we show that pumpkin- or figleaf gourd rootstock-enhanced cold tolerance of watermelon shoots is accompanied by increases in the accumulation of melatonin, methyl jasmonate (MeJA), and hydrogen peroxide $\left(\mathrm{H}_{2} \mathrm{O}_{2}\right)$. Increased melatonin levels in leaves were associated with both increased melatonin in rootstocks and MeJA-induced melatonin biosynthesis in leaves of plants under cold stress. Exogenous melatonin increased the accumulation of $\mathrm{MeJA}$ and $\mathrm{H}_{2} \mathrm{O}_{2}$ and enhanced cold tolerance, while inhibition of melatonin accumulation attenuated rootstock-induced MeJA and $\mathrm{H}_{2} \mathrm{O}_{2}$ accumulation and cold tolerance. MeJA application induced $\mathrm{H}_{2} \mathrm{O}_{2}$ accumulation and cold tolerance, but inhibition of JA biosynthesis abolished rootstock- or melatonininduced $\mathrm{H}_{2} \mathrm{O}_{2}$ accumulation and cold tolerance. Additionally, inhibition of $\mathrm{H}_{2} \mathrm{O}_{2}$ production attenuated MeJA-induced tolerance to cold stress. Taken together, our results suggest that melatonin is involved in grafting-induced cold tolerance by inducing the accumulation of $\mathrm{MeJA}$ and $\mathrm{H}_{2} \mathrm{O}_{2}$. MeJA subsequently increases melatonin accumulation, forming a self-amplifying feedback loop that leads to increased $\mathrm{H}_{2} \mathrm{O}_{2}$ accumulation and cold tolerance. This study reveals a novel regulatory mechanism of rootstock-induced cold tolerance.
\end{abstract}

\section{Introduction}

As sessile organisms, plants frequently face challenges from various environmental factors throughout their life cycle. In particular, cold stress is one of the most destructive abiotic stresses due to its adverse effects on plant growth and development and subsequent negative impacts on crop productivity ${ }^{1}$. To adapt and survive cold exposure, plants have evolved sophisticated defense mechanisms. When a plant senses that temperature decreases via molecular sensors, the production of secondary messengers is triggered, and a set of transcriptional regulators are subsequently activated to regulate plant tolerance ${ }^{2}$.

\footnotetext{
Correspondence: Xian Zhang (zhangxian@nwsuaf.edu.cn)

'State Key Laboratory of Crop Stress Biology for Arid Areas, College of

Horticulture, Northwest A\&F University, 712100 Yangling, Shaanxi, China

${ }^{2}$ College of Horticulture and Plant Protection, Henan University of Science and

Technology, 471023 Luoyang, Henan, China

Full list of author information is available at the end of the article

These authors contributed equally: Hao Li, Yanliang Guo.
}

At the whole-organism level, root-to-shoot communication is crucial for the increased survival of plants under environmental stress. Under drought conditions, roots produce more abscisic acid (ABA), which is then transported to the leaves to reduce water loss via stomatal closure $^{3}$. In many horticultural crop species, grafting is widely applied to enhance plant tolerance to various environmental stresses, such as soil-borne pathogens, salt, and low temperature. Grafting-induced plant tolerance is associated with the inherent resistance of rootstocks and some rootstock-sourced signals that are transported to shoots and subsequently regulate shoot responses ${ }^{4}$. Therefore, grafting is also a useful tool to reveal the signaling mechanisms related to root-shoot communication. For instance, by using cucumber scions grafted onto heat-tolerant luffa rootstock, $\mathrm{Li}$ et al. ${ }^{5}$ revealed that rootproduced $\mathrm{ABA}$ as a long-distance signal could alter the expression of heat shock protein (HSP) 70 and subsequently improve heat tolerance of the shoots.

\section{(c) The Author(s) 2021}

(c) (i) Open Access This article is licensed under a Creative Commons Attribution 4.0 International License, which permits use, sharing, adaptation, distribution and reproduction cc) in any medium or format, as long as you give appropriate credit to the original author(s) and the source, provide a link to the Creative Commons license, and indicate if changes were made. The images or other third party material in this article are included in the article's Creative Commons license, unless indicated otherwise in a credit line to the material. If material is not included in the article's Creative Commons license and your intended use is not permitted by statutory regulation or exceeds the permitted use, you will need to obtain permission directly from the copyright holder. To view a copy of this license, visit http://creativecommons.org/licenses/by/4.0/. 
Melatonin ( $N$-acetyl-5-methoxytryptamine) was initially identified as an essential animal hormone that has regulatory roles in various biological processes ${ }^{6}$. In 1995, melatonin was identified in vascular plants for the first time $^{7,8}$. A number of subsequent studies have shown phytomelatonin to be an essential regulator in plant growth and development; postharvest physiology; and defense against various environmental stresses, such as pathogen infection, drought, salinity, nutrient deficiency, and heavy metals ${ }^{9-11}$. In particular, the recent identification of the first phytomelatonin receptor (CAND2/ PMTR1) in Arabidopsis has opened the door to consider melatonin a new phytohormone ${ }^{12,13}$. Increasing numbers of studies have indicated that melatonin enhances the cold tolerance of various plant species, including melon, tomato, watermelon, and Arabidopsis ${ }^{14}$. Moreover, some evidence has shown melatonin to be a novel long-distance signal that can be transported from roots to shoots $^{15-17}$. Therefore, it would be interesting to investigate the involvement of melatonin in grafting-induced cold tolerance.

In plants, jasmonates (JAs) such as jasmonic acid (JA) and its methyl ester (methyl jasmonate, MeJA) act as important phytohormones that regulate multiple plant processes, such as seed germination, root growth, flowering, leaf senescence, and defense responses to various biotic and abiotic stresses ${ }^{18,19}$. Accumulating amounts of data have shown that JAs have a positive role in inducing plant tolerance to cold stress ${ }^{19}$. Cold exposure rapidly induces JA biosynthesis-related genes and subsequent JA accumulation ${ }^{20}$. Moreover, exogenous application of MeJA enhances Arabidopsis tolerance to cold, while mutants defective in JA biosynthesis or signaling exhibit hypersensitivity to cold stress ${ }^{19}$. Recent studies involving grafting experiments have shown that JA is involved in root and shoot communication to fine-tune plant responses to shoot wounding and root-knot nematodes $^{21,22}$. However, little is known about the involvement of JA in root-shoot communication under cold stress.

Watermelon is a widely cultivated vegetable crop species worldwide and is very sensitive to cold stress ${ }^{23}$. Grafting onto pumpkin can induce watermelon tolerance to $\operatorname{cold}^{24,25}$. Our recent study suggests that melatonin application to the roots can confer cold tolerance to the shoot via xylem transport, and such induction involves the expression of several genes involved in JA signaling and the production of $\mathrm{H}_{2} \mathrm{O}_{2}{ }^{17}$, an important secondary messenger in the cold response ${ }^{26}$. This raises the possibility that melatonin has an important role in rootstock-induced shoot tolerance against the cold by interacting with JA and $\mathrm{H}_{2} \mathrm{O}_{2}$. To test this assumption, the present study evaluated the roles of melatonin, MeJA, and $\mathrm{H}_{2} \mathrm{O}_{2}$ and their interaction in rootstock-induced cold tolerance. Our results provide convincing evidence that melatonin-induced cold tolerance of grafted watermelon plants essentially involves MeJA and $\mathrm{H}_{2} \mathrm{O}_{2}$ signaling. This study provides novel insight into the mechanism of rootstock-induced cold tolerance in cucurbits.

\section{Materials and methods \\ Plant materials}

Three cucurbit species, namely, watermelon (Citrullus lanatus (Thunb.) Matsum. \& Nakai cv. Nongkeda No. 5, Cl), pumpkin (Cucurbita moschata Duch cv. Weizhen No. $1, C m$ ), and figleaf gourd (Cucurbita ficifolia Bouché, Cf), were used in the current study. Germinated seeds of $\mathrm{Cl}$, $C m$, and $C f$ as rootstocks were sown into plastic pots $(7 \times$ $7 \times 7.5 \mathrm{~cm}$ (length $\times$ width $\times$ height, respectively)) filled with $210 \mathrm{~cm}^{3}$ of commercial peat-based compost, and $7 \mathrm{~d}$ later, germinated seeds of $\mathrm{Cl}$ (as scions) were sown. Top insertion grafts were performed when the cotyledons of watermelon (as scions) had fully expanded ${ }^{27}$. The resulting three groups of grafted seedlings were designated $\mathrm{Cl} / \mathrm{Cl}, \mathrm{Cl} / \mathrm{Cm}$, and $\mathrm{Cl} / \mathrm{Cf} ; \mathrm{Cl} / \mathrm{Cl}$ plants were used as control. The plants were grown in growth chambers with a temperature of $25 / 18^{\circ} \mathrm{C}$ (day/night), a 12 -h photoperiod, and photosynthetic photon flux density (PPFD) of $400 \mu \mathrm{mol} \mathrm{m}{ }^{-2} \mathrm{~s}^{-1}$. The seedlings were watered every $2 \mathrm{~d}$ and supplied with Hoagland's nutrient solution every $3 \mathrm{~d}$.

\section{Experimental design}

Experiment 1. To evaluate the effects of different rootstocks on scion tolerance to cold stress, $\mathrm{Cl} / \mathrm{Cl}, \mathrm{Cl} / \mathrm{Cm}$, and $\mathrm{Cl} / \mathrm{Cf}$ plants with four true leaves were transferred into growth chambers maintained at $25{ }^{\circ} \mathrm{C}$ for the control treatment or $4{ }^{\circ} \mathrm{C}$ for cold treatment. At $0,6,12,18$, and $24 \mathrm{~h}$ after cold treatment, the relative expression levels of C-REPEAT BINDING FACTOR 1 (ClCBF1) and ClCBF2 were measured. At $36 \mathrm{~h}$ after cold treatment, the maximum photochemical efficiency of PSII $(F v / F m)$ and the relative electrical conductivity (REC) were measured. At $12 \mathrm{~h}$ after cold treatment, root or leaf samples were harvested for biochemical assays.

Experiment 2. To determine the effects of exogenous melatonin, MeJA, and $\mathrm{H}_{2} \mathrm{O}_{2}$ on the cold tolerance of $\mathrm{Cl} / \mathrm{Cl}$ seedlings, the leaves were first sprayed with distilled water (as a control), melatonin at $150 \mu \mathrm{M}^{17}, \mathrm{MeJA}$ at $200 \mu \mathrm{M}^{19}$, or $\mathrm{H}_{2} \mathrm{O}_{2}$ at $2 \mathrm{mM}^{5}$. Melatonin (Sigma-Aldrich, St. Louis, MO, USA) or MeJA (Sigma-Aldrich) was dissolved in ethanol followed by dilution with distilled water at a ratio of $1 / 10,000(\mathrm{v} / \mathrm{v})$. Each plant was sprayed with $20 \mathrm{~mL}$ of the respective chemical solution or distilled water (as a control). At $12 \mathrm{~h}$ after pretreatment with melatonin, MeJA, or $\mathrm{H}_{2} \mathrm{O}_{2}$, the plants were subjected to $4{ }^{\circ} \mathrm{C}$ temperature. To block the synthesis or accumulation of melatonin, JA, or $\mathrm{H}_{2} \mathrm{O}_{2}$ in $\mathrm{Cl} / \mathrm{Cl}$ plants, the leaves were pretreated with $100 \mu \mathrm{M} p$-chlorophenylalanine (CPA, a melatonin synthesis inhibitor) ${ }^{28,29}, 5 \mathrm{mM}$ diethyldithiocarbamic acid 
(DIECA, a JA biosynthesis inhibitor) ${ }^{30}$, or $20 \mu \mathrm{M}$ diphenylene iodonium (DPI, an inhibitor of NADPH oxidase, which produces $\left.\mathrm{H}_{2} \mathrm{O}_{2}\right)^{31}$. Eight hours later, the plants were sprayed with melatonin or MeJA, and $12 \mathrm{~h}$ later, they were exposed to $4{ }^{\circ} \mathrm{C}$.

Experiment 3. To assess the involvement of melatonin, MeJA, and $\mathrm{H}_{2} \mathrm{O}_{2}$ and their interactions in rootstockinduced cold tolerance, the leaves of $\mathrm{Cl} / \mathrm{Cm}$ and $\mathrm{Cl} / \mathrm{Cf}$ seedlings were sprayed with CPA, DIECA, or DPI $8 \mathrm{~h}$ prior to cold exposure. The leaves were sampled at $12 \mathrm{~h}$, whereas the $F v / F m$ and REC were measured at $36 \mathrm{~h}$ after cold exposure.

\section{Cold tolerance assays}

The $F v / F m$ was measured using an imaging pulseamplitude-modulated (PAM) chlorophyll fluorometer (Heinz Walz, GmbH, Effeltrich, Germany) according to the method described by Li et al. ${ }^{5}$. The REC was determined and calculated as described by Hong et al. ${ }^{32}$.

\section{Melatonin measurements}

Melatonin was extracted and measured as described previously $y^{33}$. Frozen samples $(0.5 \mathrm{~g})$ were homogenized in 5 $\mathrm{mL}$ of acetone-methanol buffer (acetone/methanol/water $=89 / 10 / 1)$ on ice. After centrifugation $\left(5,000 \mathrm{~g}, 4{ }^{\circ} \mathrm{C}\right)$ for $10 \mathrm{~min}, 0.5 \mathrm{~mL}$ of trichloric acid (1\%) was added to the supernatant for protein precipitation. After centrifugation at $10,000 \times g$ for $10 \mathrm{~min}$ at $4{ }^{\circ} \mathrm{C}$, the supernatants were used to quantify melatonin levels using an ELISA kit (Shanghai Lanpai Biotechnology Co., Ltd., Shanghai, China) according to the manufacturer's instructions.

\section{Quantification of MeJA}

MeJA was extracted as described by Pan et al. ${ }^{34}$. For the extraction of MeJA, $0.5 \mathrm{~g}$ of frozen leaf samples was homogenized in $5 \mathrm{~mL}$ of 1-propanol $/ \mathrm{H}_{2} \mathrm{O} /$ concentrated $\mathrm{HCl}(2 / 1 / 0.002, \mathrm{v} / \mathrm{v} / \mathrm{v})$ and subsequently incubated overnight. The extracts and $5 \mathrm{~mL}$ of dichloromethane were then mixed together, after which the mixture was shaken at $4{ }^{\circ} \mathrm{C}$ for $30 \mathrm{~min}$. After centrifugation, the obtained lower phase was dried under a stream of $\mathrm{N}_{2}$ gas. The residue was then dissolved in methanol. MeJA concentrations were analyzed using an ELISA kit (China Agricultural University, Beijing, China) following the manufacturer's instructions.

\section{Analysis of $\mathrm{H}_{2} \mathrm{O}_{2}$}

$\mathrm{H}_{2} \mathrm{O}_{2}$ in the leaf samples was measured as described by Bellincampi et al. ${ }^{35}$. Briefly, the leaf material $(0.3 \mathrm{~g})$ was homogenized in $2 \mathrm{~mL}$ of $0.2 \mathrm{M} \mathrm{HClO}_{4}$. After centrifugation $\left(10,000 \times g, 4{ }^{\circ} \mathrm{C}\right)$ for $15 \mathrm{~min}$, an aliquot of supernatant $(0.5 \mathrm{~mL})$ was added to $0.5 \mathrm{~mL}$ of assay reagent consisting of $500 \mu \mathrm{M}$ ammonium ferrous sulfate, $200 \mu \mathrm{M}$ xylenol orange, $50 \mathrm{mM} \mathrm{H}_{2} \mathrm{SO}_{4}$, and $200 \mathrm{mM}$

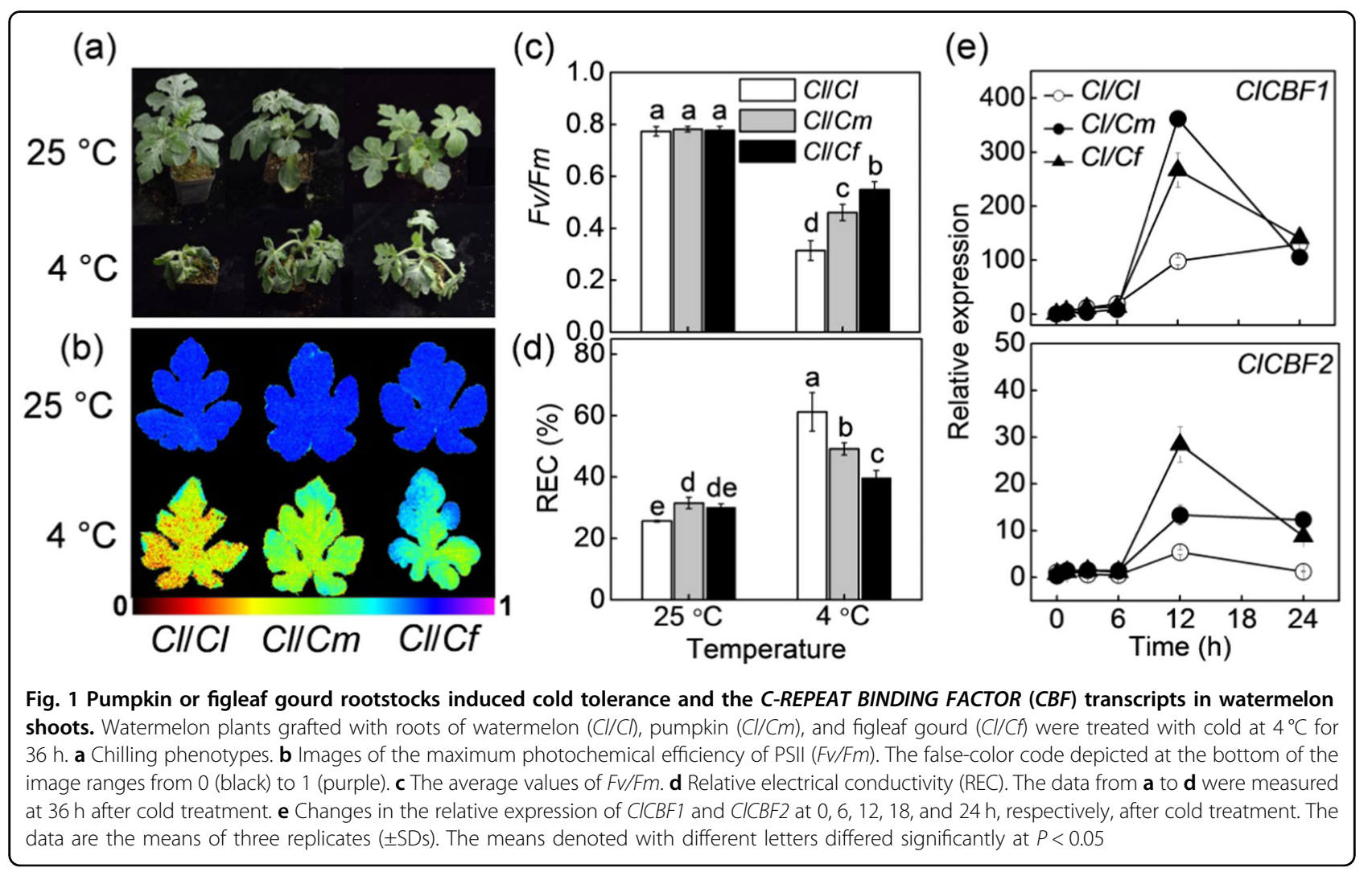


sorbitol. After incubation for $1 \mathrm{~h}$, the absorbance at $\mathrm{OD}_{560}$ was recorded. DAB staining of $\mathrm{H}_{2} \mathrm{O}_{2}$ was performed following the protocol described by Thordal-Christensen et $\mathrm{al}^{36}$.

\section{qRT-PCR analysis}

Total RNA was extracted from the leaves using an RNA extraction kit (AxGen, Union City, CA, USA). Residual DNA was removed using a DNase Mini Kit (Qiagen, Hilden, Germany). The isolated total RNA $(1 \mu \mathrm{g})$ was reverse transcribed using a ReverTra Ace qPCR RT Kit (Toyobo, Osaka, Japan). qRT-PCR was then performed using an iCycler iQ Multicolor PCR Detection System (Bio-Rad, Hercules, CA, USA) as described by Li et al. ${ }^{17}$. The primers used for qRT-PCR are listed in Supplementary Table S1. The relative expression levels were standardized to those of watermelon $\beta$-ACTIN and were calculated as described by Livak and Schmittgen ${ }^{37,38}$.

\section{Statistical analysis}

The experiment was carried out in accordance with a completely randomized design, with three independent biological replicates. Each replicate included 15 plants. For statistical analysis, the data were analyzed using variance (ANOVA), and $P$ values $<0.05$ were considered statistically significant according to Tukey's test.

\section{Results}

\section{Pumpkin and figleaf gourd rootstocks induced cold} tolerance in watermelon shoots

We first compared the leaf phenotypes, $F v / F m$ values, and REC of watermelon plants grafted onto the rootstocks of watermelon $(\mathrm{Cl} / \mathrm{Cl})$, pumpkin $(\mathrm{Cl} / \mathrm{Cm})$, and figleaf gourd $(\mathrm{Cl} / \mathrm{Cf})$. Under normal conditions at $25{ }^{\circ} \mathrm{C}$, no significant differences in plant growth or $\mathrm{Fv} / \mathrm{Fm}$ were observed among the different grafted plants, although the REC of the $\mathrm{Cl} / \mathrm{Cm}$ and $\mathrm{Cl} / \mathrm{Cf}$ plants was slightly higher than that of the $\mathrm{Cl} / \mathrm{Cl}$ plants (Fig. 1a-d). Cold stress caused severe leaf wilting, a significant decrease in $\mathrm{Fv} / \mathrm{Fm}$, and an increase in REC of the $\mathrm{Cl} / \mathrm{Cl}$ plants. However, pumpkin and especially figleaf gourd as rootstocks alleviated the cold-induced wilting, $F v / F m$ decrease, and REC increase in watermelon leaves. For example, the $F v / F m$ of $\mathrm{Cl} / \mathrm{Cm}$ and $\mathrm{Cl} / \mathrm{Cf}$ plants were 0.46 and 0.55 , respectively, which was much higher than that $(0.31)$ of $\mathrm{Cl} / \mathrm{Cl}$ plants at $36 \mathrm{~h}$ after cold exposure.

The relative expression of $C l C B F 1$ and $C l C B F 2$ was upregulated after cold treatment, and the highest peak occurred at $12 \mathrm{~h}$ in nearly all of the grafted plants; however, the highest expression of $\mathrm{ClCBF1}$ in the $\mathrm{Cl} / \mathrm{Cl}$ plants occurred at $24 \mathrm{~h}$ after cold exposure (Fig. 1e). Importantly, $\mathrm{Cl} / \mathrm{Cm}$ and $\mathrm{Cl} / \mathrm{Cf}$ plants showed more significant increases in transcript levels of $C l C B F 1$ and $C l C B F 2$ than did $\mathrm{Cl} / \mathrm{Cl}$ plants after cold exposure. For example, $C l C B F 1$

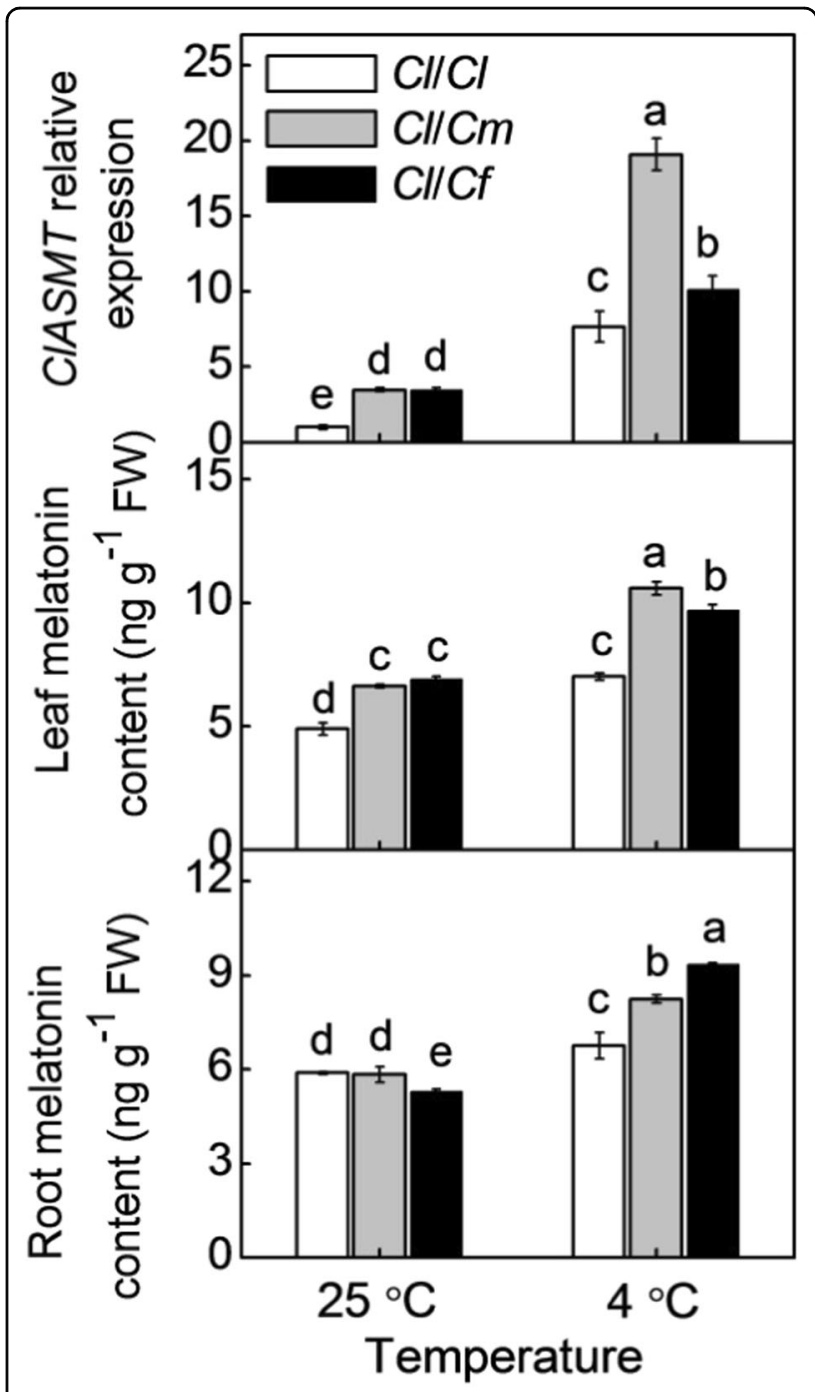

Fig. 2 The transcript abundance of $N$-ACETYLSEROTONIN O-METHYLTRANSFERASE (CIASMT) and melatonin accumulation in response to different rootstocks and cold stress. The seedlings were treated as described in Fig. 1. Root and leaf samples were harvested at $12 \mathrm{~h}$ after the cold exposure. The data are presented as the means of three replicates $( \pm S D s)$. The means denoted with different letters differ significantly at $P<0.05$

transcript levels were upregulated 98.1-, 361.6-, and 266.4-fold in $\mathrm{Cl} / \mathrm{Cl}, \mathrm{Cl} / \mathrm{Cm}$, and $\mathrm{Cl} / \mathrm{Cf}$ plants, respectively, while the $C l C B F 2$ transcripts were upregulated 5.3-, 13.3-, and 28.4-fold, respectively, at $12 \mathrm{~h}$ after cold stress.

Different rootstocks induced melatonin accumulation differently in leaves of watermelon plants under cold stress

At the optimum growth temperature, the melatonin contents in pumpkin and figleaf gourd roots were similar to and lower than those in watermelon roots, respectively (Fig. 2). However, both pumpkin and figleaf gourd as 


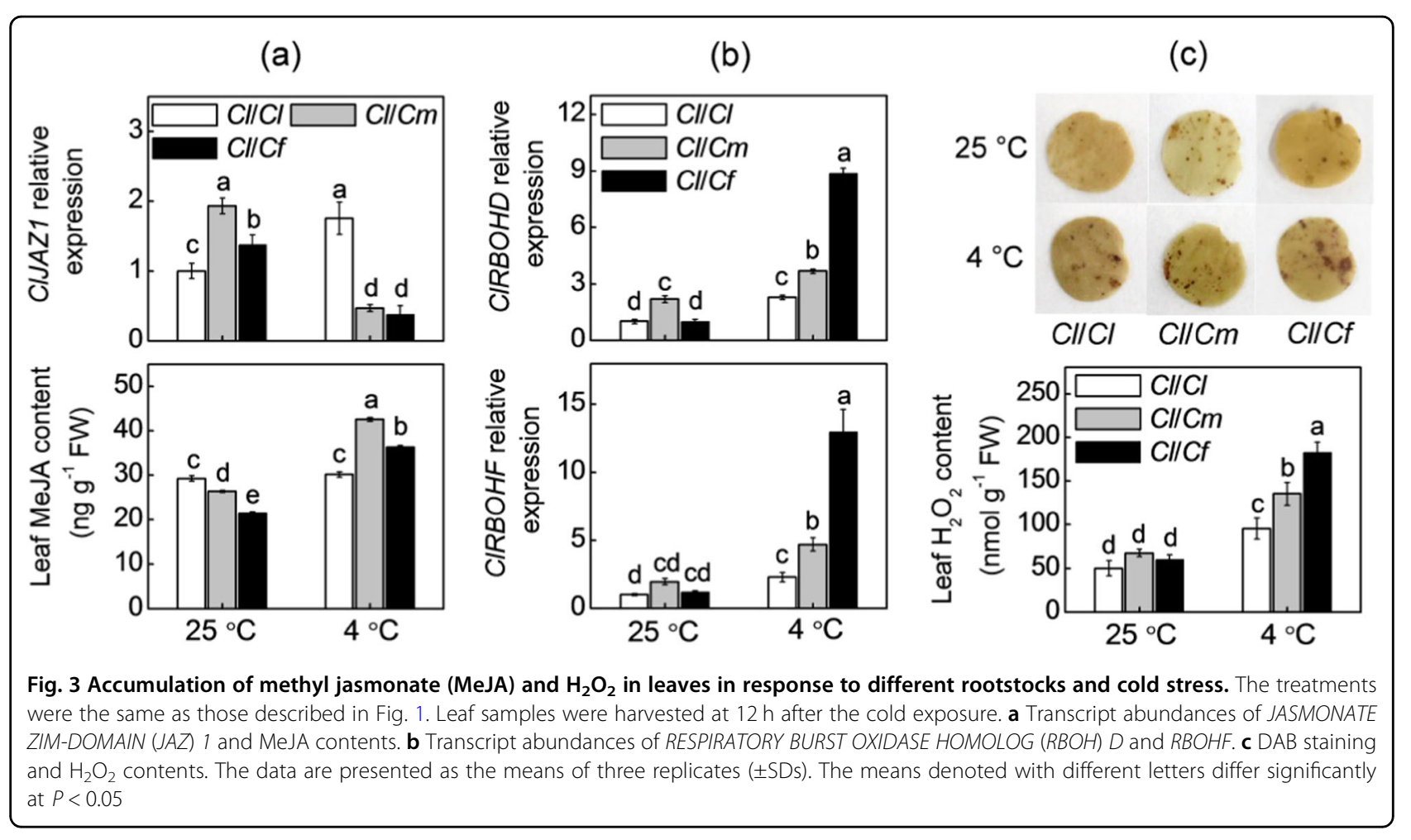

rootstocks increased the melatonin contents and increased the relative expression of $N$-ACETYLSEROTONIN OMETHYLTRANSFERASE (ClASMT), a key gene involved in melatonin biosynthesis, in the leaves. Cold stress-induced melatonin accumulation in both the roots and leaves and upregulated the relative expression of ClASMT in the leaves of all grafted seedlings at $12 \mathrm{~h}$ after cold treatment. Interestingly, the melatonin contents in the roots of $\mathrm{Cl} / \mathrm{Cm}$ and especially $\mathrm{Cl} / \mathrm{Cf}$ were obviously higher than those in the $\mathrm{Cl} / \mathrm{Cl}$ roots after cold exposure. Moreover, the levels of melatonin and ClASMT transcripts in the $\mathrm{Cl} / \mathrm{Cm}$ and $\mathrm{Cl} / \mathrm{Cf}$ leaves were also higher than those in the $\mathrm{Cl} / \mathrm{Cl}$ leaves.

\section{Pumpkin and figleaf gourd rootstocks induced MeJA and} $\mathrm{H}_{2} \mathrm{O}_{2}$ accumulation in leaves of watermelon plants under cold stress

Under normal conditions at $25{ }^{\circ} \mathrm{C}$, pumpkin or figleaf gourd as rootstocks decreased the MeJA contents but increased the relative expression of JASMONATE ZIMDOMAIN 1 (ClJAZ1, a repressor gene involving in JA signaling) in watermelon leaves (Fig. 3a). The MeJA content in $\mathrm{Cl} / \mathrm{Cl}$ leaves was almost unchanged after exposure to cold stress; however, that in $\mathrm{Cl} / \mathrm{Cm}$ and $\mathrm{Cl} / \mathrm{Cf}$ leaves significantly increased. The MeJA contents in the $\mathrm{Cl} / \mathrm{Cm}$ and $\mathrm{Cl} / \mathrm{Cf}$ leaves were $40.4 \%$ and $19.7 \%$ higher than those in the $\mathrm{Cl} / \mathrm{Cl}$ leaves, respectively, at $12 \mathrm{~h}$ after cold stress. The relative expression of ClJAZ1 was upregulated in the $\mathrm{Cl} / \mathrm{Cl}$ leaves but downregulated in the $\mathrm{Cl} /$ $\mathrm{Cm}$ and $\mathrm{Cl} / \mathrm{Cf}$ leaves of plants under cold stress.
Unexpectedly, no significant differences were observed in root MeJA content among the different grafted plants under cold stress (Supplementary Fig. S1).

The $\mathrm{H}_{2} \mathrm{O}_{2}$ generated by RESPIRATORY BURST OXI$D A S E$ HOMOLOG $(R B O H)$ functions as an important signaling molecule in regulating plant tolerance to cold stress. Thus, we investigated whether $\mathrm{H}_{2} \mathrm{O}_{2}$ is involved in rootstock-induced cold tolerance. At optimum growth temperatures, pumpkin as a rootstock induced the accumulation of $C l R B O H D$ transcripts in watermelon leaves compared to watermelon rootstocks (Fig. 3b). However, there were no significant differences in ClRBOHF transcripts or $\mathrm{H}_{2} \mathrm{O}_{2}$ content among any of the grafted plants (Fig. 3b, c). Exposure to $4{ }^{\circ} \mathrm{C}$ increased $\mathrm{H}_{2} \mathrm{O}_{2}$ accumulation and $C l R B O H D$ and $C l R B O H F$ transcript levels in all grafted plants. The leaves of $C l / C m$ and especially $C l / C f$ plants showed higher $\mathrm{H}_{2} \mathrm{O}_{2}$ levels and $C l R B O H D / F$ transcripts than did those of $\mathrm{Cl} / \mathrm{Cm}$ under cold stress. For example, the $\mathrm{H}_{2} \mathrm{O}_{2}$ contents in the $\mathrm{Cl} / \mathrm{Cm}$ and $\mathrm{Cl} / \mathrm{Cf}$ leaves were $41.8 \%$ and $91.3 \%$ higher than those in the $\mathrm{Cl} /$ $\mathrm{Cl}$ leaves, respectively, after cold exposure.

\section{Role of melatonin in rootstock-induced accumulation of MeJA and $\mathrm{H}_{2} \mathrm{O}_{2}$ and cold tolerance}

To evaluate the role of melatonin in rootstockinduced cold tolerance, we first analyzed the effect of exogenous melatonin on the cold tolerance of $\mathrm{Cl} / \mathrm{Cl}$ plants. Melatonin $(150 \mu \mathrm{M})$ pretreatment alleviated the cold-induced $F v / F m$ decrease and REC increase 

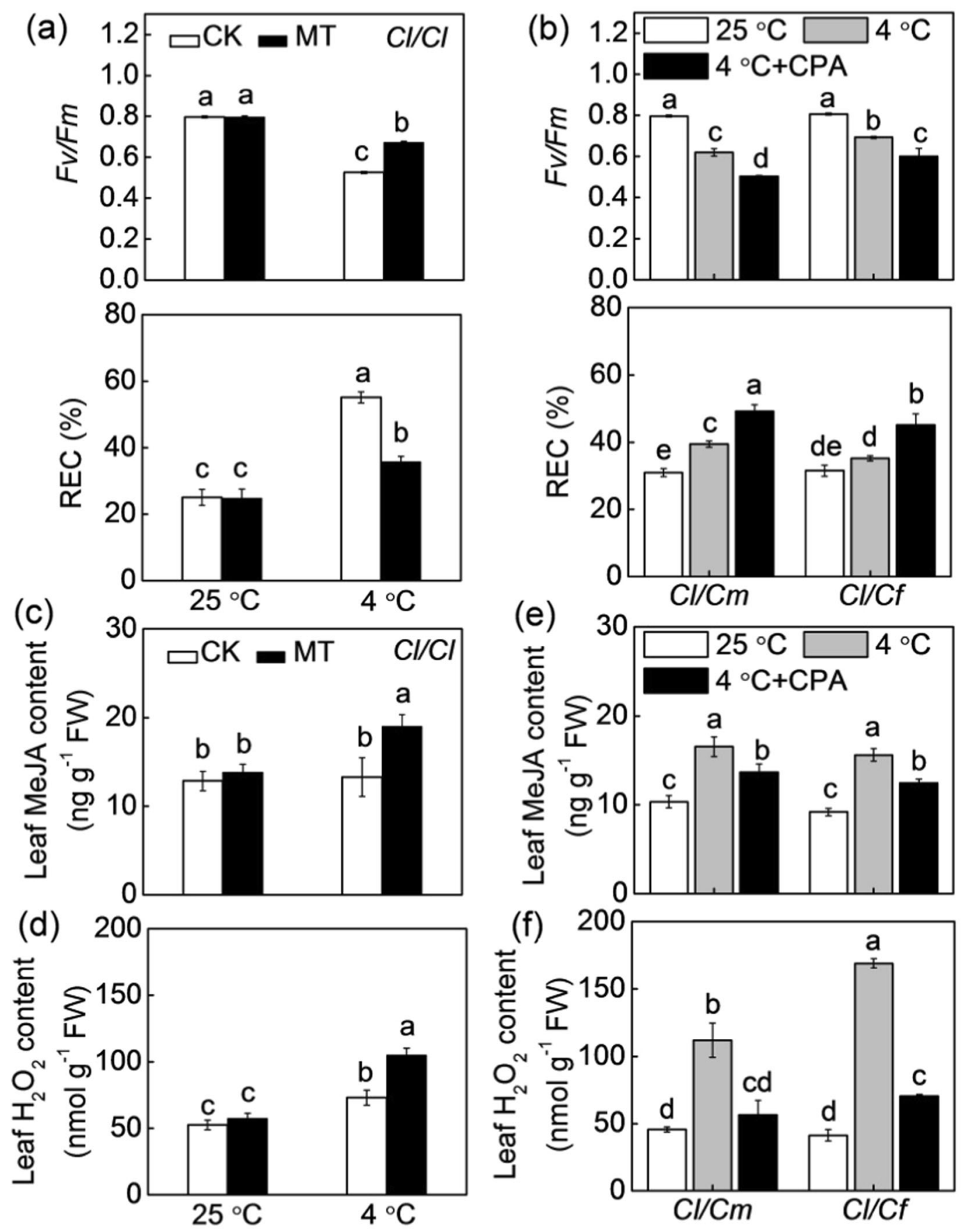

Fig. 4 Involvement of melatonin in pumpkin or figleaf gourd rootstock-induced cold tolerance and accumulation of $\mathrm{MeJA}$ and $\mathrm{H}_{2} \mathrm{O}_{2}$ in watermelon leaves. a Changes in the FV/Fm and REC of watermelon plants grafted onto watermelon (Cl/Cl). $\mathbf{b}$ Changes in the FV/Fm and REC of watermelon plants grafted onto pumpkin $(\mathrm{Cl} / \mathrm{Cm})$ or figleaf gourd $(\mathrm{Cl} / \mathrm{Cf})$. c MeJA and $\mathbf{d} \mathrm{H}_{2} \mathrm{O}_{2}$ contents in $\mathrm{Cl} / \mathrm{Cl}$ plants. e MeJA and $\mathbf{f} \mathrm{H}_{2} \mathrm{O}_{2}$ contents in $\mathrm{Cl} / \mathrm{Cm}$ and $\mathrm{Cl} / \mathrm{Cf}$ plants. For $\mathbf{a}, \mathbf{c}$, and $\mathbf{d}$, the leaves were sprayed with melatonin $(150 \mu \mathrm{M}) 12 \mathrm{~h}$ prior to cold exposure at $4{ }^{\circ} \mathrm{C}$. For $\mathbf{b}$, e, and $\mathbf{f}$, the leaves were sprayed with $p$-chlorophenylalanine $(\mathrm{CPA}, 100 \mu \mathrm{M}) 8 \mathrm{~h}$ prior to cold exposure at $4^{\circ} \mathrm{C}$. The data from $\mathbf{a}$ and $\mathbf{b}$ were determined at $36 \mathrm{~h}$ after cold exposure. MeJA and $\mathrm{H}_{2} \mathrm{O}_{2}$ were measured at $12 \mathrm{~h}$ after cold treatment. The data are the means of three replicates $( \pm \mathrm{SDs})$. The means denoted with different letters differ significantly at $P<0.05$

(Fig. 4a). In melatonin-pretreated plants, the $F v / F m$ was $14.8 \%$ higher while the REC was $35.0 \%$ lower after exposure to cold stress than in the control plants. As
CPA application can prevent melatonin biosynthesis ${ }^{29}$, we thus evaluated the effect of CPA on the cold tolerance of $\mathrm{Cl} / \mathrm{Cm}$ and $\mathrm{Cl} / \mathrm{Cf}$ plants. Pretreatment with $\mathrm{CPA}$ 


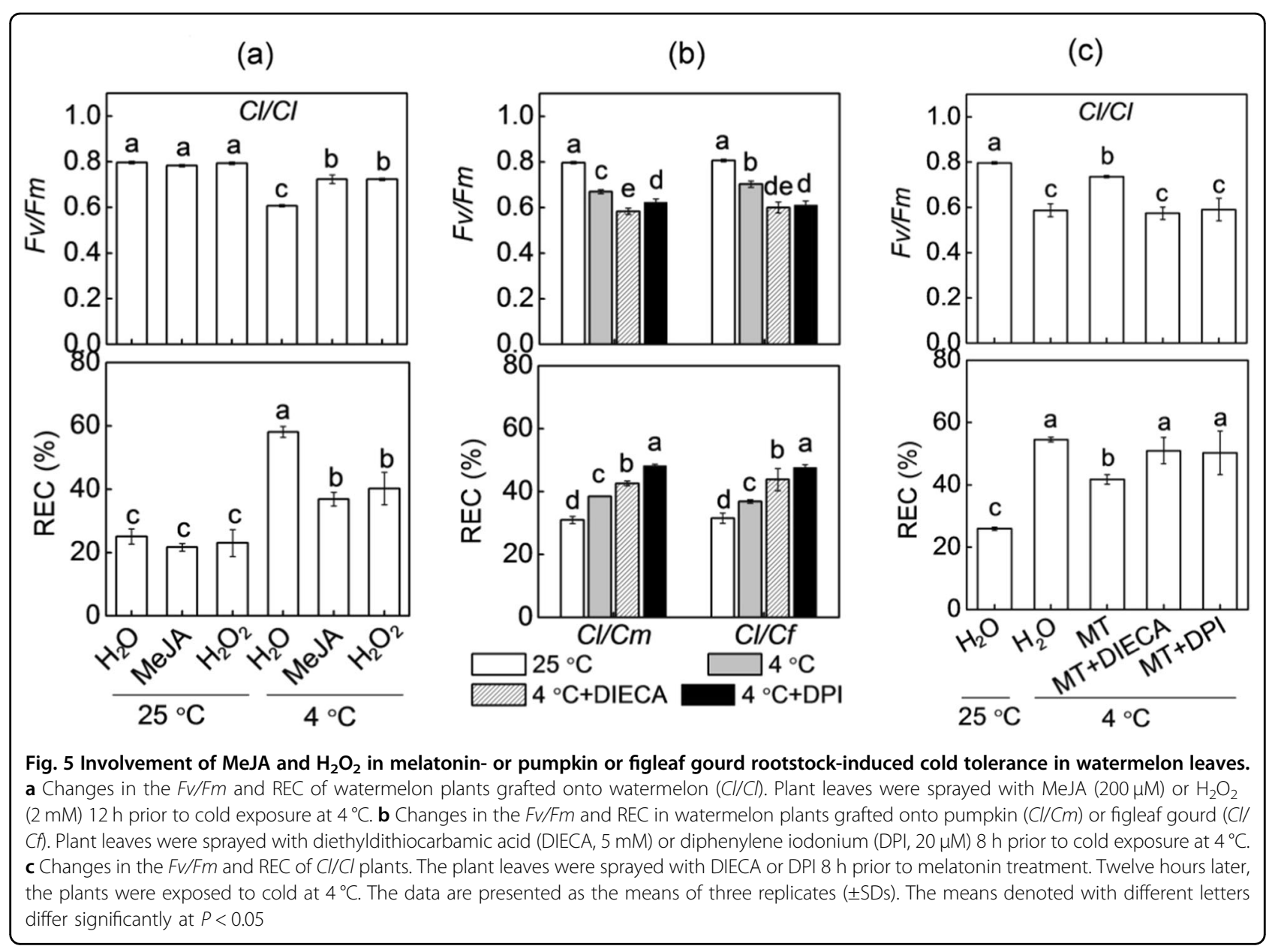

attenuated the pumpkin- and figleaf gourd rootstockinduced alleviation of cold stress, as reflected by the $\mathrm{Fv} / \mathrm{Fm}$ decrease and REC increase (Fig. 4b).

At the optimum growth temperatures, exogenous melatonin application did not induce significant changes in MeJA and $\mathrm{H}_{2} \mathrm{O}_{2}$ levels in $\mathrm{Cl} / \mathrm{Cl}$ leaves (Fig. 4c, d). However, the contents of MeJA and $\mathrm{H}_{2} \mathrm{O}_{2}$ increased by $42.9 \%$ and $44.1 \%$, respectively, in response to melatonin under cold stress. More importantly, pretreatment with CPA attenuated or completely blocked pumpkin- and figleaf gourd rootstock-induced increases in MeJA and $\mathrm{H}_{2} \mathrm{O}_{2}$ accumulation in the leaves (Fig. 4e, f). These data suggest that melatonin has an important role in pumpkin- or figleaf gourd rootstock-induced accumulation of MeJA and $\mathrm{H}_{2} \mathrm{O}_{2}$ and cold tolerance.

\section{Roles of MeJA and $\mathrm{H}_{2} \mathrm{O}_{2}$ in melatonin- or rootstock-} induced cold tolerance

To evaluate the roles of MeJA and $\mathrm{H}_{2} \mathrm{O}_{2}$ in cold tolerance acquired by grafting and melatonin, we first evaluated the effects of foliar applications of MeJA or $\mathrm{H}_{2} \mathrm{O}_{2}$ on the cold tolerance of $\mathrm{Cl} / \mathrm{Cl}$ plants. Both MeJA $(200 \mu \mathrm{M})$ and $\mathrm{H}_{2} \mathrm{O}_{2}(2 \mathrm{mM})$ application alleviated the cold-induced decrease in $\mathrm{Fv} / \mathrm{Fm}$ and increase in REC of $\mathrm{Cl} / \mathrm{Cl}$ plants (Fig. 5a). Pretreatment with DIECA (an inhibitor of JA biosynthesis, $5 \mathrm{mM}$ ) or DPI (an inhibitor of $\mathrm{H}_{2} \mathrm{O}_{2}$ production, $20 \mu \mathrm{M}$ ) attenuated or abolished the pumpkin- or figleaf gourd rootstock-induced alleviation of cold stress, as reflected by a decline in $\mathrm{Fv} / \mathrm{Fm}$ and an increase in REC (Fig. 5b). Furthermore, DIECA or DPI application also prevented the melatonin-induced $F v / F m$ increase and REC decrease after exposure to cold stress (Fig. 5c). Taken together, these results suggest that MeJA and $\mathrm{H}_{2} \mathrm{O}_{2}$ are involved in melatonin- or rootstockinduced cold tolerance.

\section{Role of MeJA in rootstock-induced accumulation of melatonin and $\mathrm{H}_{2} \mathrm{O}_{2}$}

To evaluate whether MeJA regulates melatonin biosynthesis in a feedback manner, we analyzed the response of melatonin to MeJA. The application of MeJA significantly increased melatonin accumulations in the $\mathrm{Cl} / \mathrm{Cl}$ leaves after cold stress (Fig. 6a), while DIECA attenuated the pumpkin- or figleaf gourd rootstock-induced increase in melatonin contents (Fig. 6b). Moreover, CPA pretreatment attenuated the MeJA-induced $F v / F m$ increase 
(a)

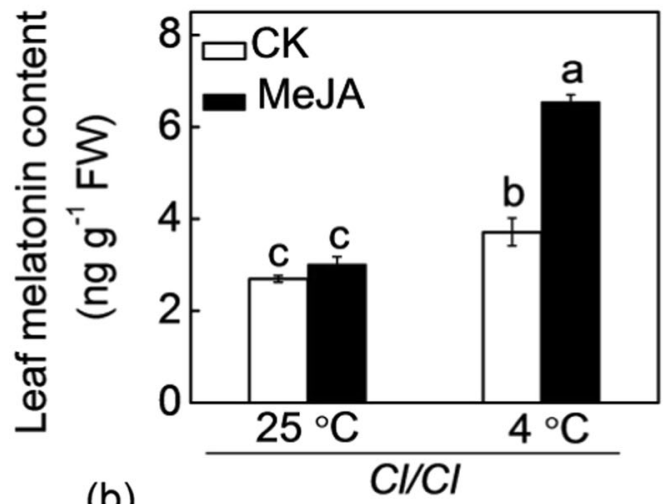

(b)

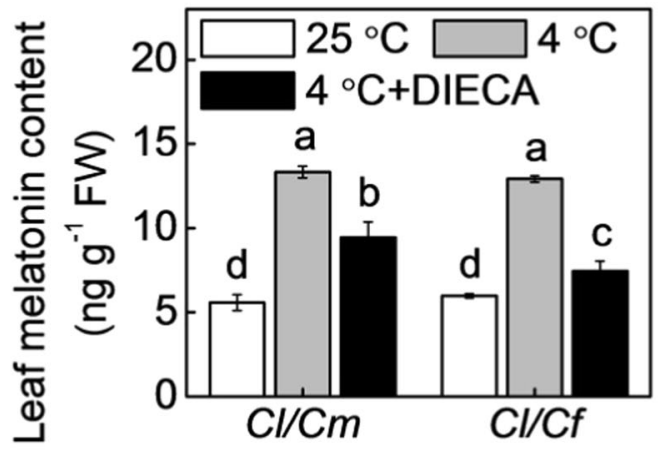

(c)

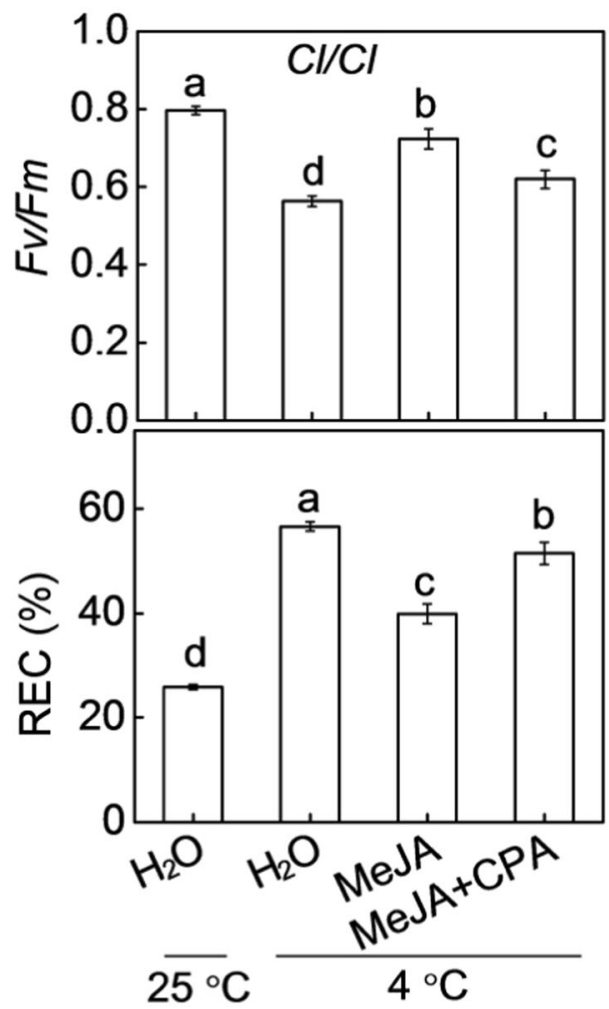

Fig. 6 Involvement of melatonin in MeJA-induced cold tolerance of grafted watermelon plants. a Changes in melatonin contents in watermelon plants grafted onto watermelon rootstock (Cl/Cl). Seedlings were pretreated with MeJA (200 $\mu \mathrm{M})$ and then subjected to $4{ }^{\circ} \mathrm{C}$ for $12 \mathrm{~h}$. b Changes in melatonin contents in watermelon plants grafted onto pumpkin $(\mathrm{Cl} / \mathrm{Cm})$ or figleaf gourd $(\mathrm{Cl} / \mathrm{Cf})$. Leaves were pretreated with DIECA $8 \mathrm{~h}$ prior to cold exposure at $4^{\circ} \mathrm{C}$ for $12 \mathrm{~h}$. c Changes in the FV/Fm and REC of Cl/Cl plants. Plants were pretreated with CPA, and $8 \mathrm{~h}$ later, the plants were sprayed with MeJA. Twelve hours later, the plants were subjected to $4^{\circ} \mathrm{C}$ for $36 \mathrm{~h}$. The data are presented as the means of three replicates $( \pm S D s)$. The means denoted with different letters differ significantly at $P<0.05$

and REC decrease of $\mathrm{Cl} / \mathrm{Cl}$ leaves of plants under cold stress (Fig. 6c).

To further characterize the role of $\mathrm{H}_{2} \mathrm{O}_{2}$ in MeJAenhanced cold tolerance, we first evaluated the effects of MeJA on $\mathrm{H}_{2} \mathrm{O}_{2}$ accumulation in $\mathrm{Cl} / \mathrm{Cl}$ plants. MeJA application induced an increase in $\mathrm{H}_{2} \mathrm{O}_{2}$ accumulation under cold stress (Fig. 7a), while DIECA pretreatment completely abolished the melatonin-induced increase in $\mathrm{H}_{2} \mathrm{O}_{2}$. Similarly, DIECA also completely blocked the pumpkin- and figleaf gourd rootstock-induced increase in $\mathrm{H}_{2} \mathrm{O}_{2}$ accumulation under cold stress (Fig. 7b). Furthermore, DPI pretreatment attenuated the MeJA-induced alleviation of cold stress, as reflected by the $F v / F m$ decrease and REC increase (Fig. 7c).

\section{Discussion}

Melatonin is involved in rootstock-induced cold tolerance

Grafting onto tolerant rootstocks is well known to enhance plant tolerance to various environmental stresses, such as soil-borne pathogens, cold, and salinity.
Consistent with the findings of previous studies ${ }^{24,25}$, we found that the rootstocks of pumpkin or figleaf gourd enhanced watermelon tolerance to cold stress (Fig. 1). By using RNA-seq analysis, $\mathrm{Xu}$ et $\mathrm{al}^{39}$ found that pumpkin rootstocks could alter the expression of COLDRESPONSIVE (COR) genes in shoots of watermelon plants under chilling stress. CBFs, the major activators of a subset of $C O R$ genes, have essential roles in modulating plant responses to cold stress ${ }^{40}$. In the present study, pumpkin or figleaf gourd as rootstocks significantly increased the transcripts of $C l C B F 1$ and $C l C B F 2$ in watermelon leaves after cold exposure (Fig. 1e). Therefore, it is plausible that some long-distance signal(s) originating from rootstocks are involved in inducing the shoot response to cold stress.

Increasing amounts of evidence have demonstrated that melatonin can induce cold tolerance in various plant species, and such induction is associated with the upregulated expression of $C B F \mathrm{~s}^{41,42}$. Here, we observed that pumpkin or figleaf gourd rootstocks increased the 
(a)
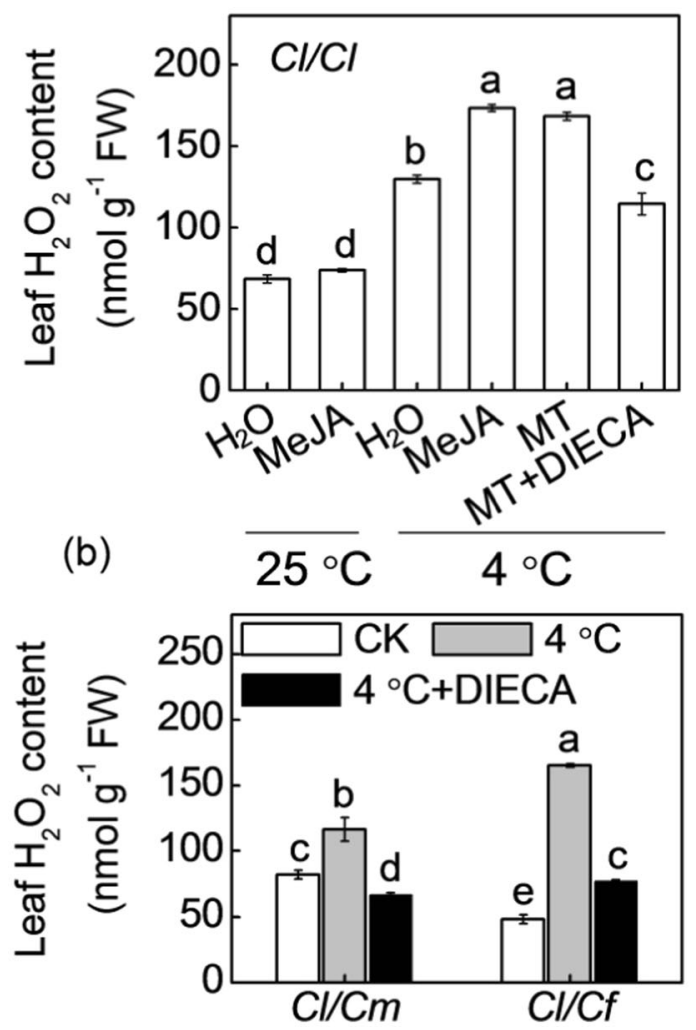

(c)
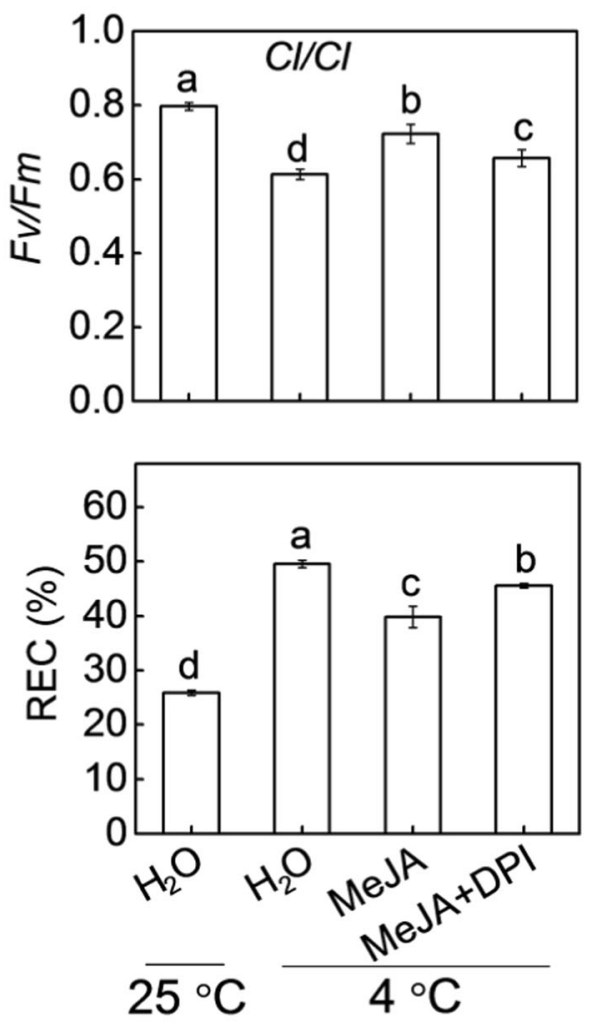

Fig. 7 Involvement of $\mathrm{H}_{2} \mathrm{O}_{2}$ in MeJA-induced cold tolerance of grafted watermelon plants. a Changes in $\mathrm{H}_{2} \mathrm{O}_{2}$ contents in watermelon plants grafted onto watermelon (CI/Ch). Seedlings were pretreated with or without DIECA, and $8 \mathrm{~h}$ later, the plants were sprayed with MeJA or melatonin. After $12 \mathrm{~h}$, the plants were subjected to $4^{\circ} \mathrm{C}$ for $12 \mathrm{~h}$. b Changes in $\mathrm{H}_{2} \mathrm{O}_{2}$ contents in watermelon plants grafted onto pumpkin $(\mathrm{Cl} / \mathrm{Cm})$ or figleaf gourd (CI/Cf). Plant leaves were sprayed with DIECA, and $8 \mathrm{~h}$ later, the plants were subjected to $4^{\circ} \mathrm{C}$ for $12 \mathrm{~h}$. $\mathrm{c}$ Changes in $\mathrm{FV} / \mathrm{Fm}$ and $\mathrm{REC}$ of $\mathrm{Cl} / \mathrm{Cl}$ plants. Plants were pretreated with DPl, and $8 \mathrm{~h}$ later, the plants were sprayed with MeJA. After $12 \mathrm{~h}$, the plants were subjected to $4^{\circ} \mathrm{C}$ for $36 \mathrm{~h}$. The data are presented as the means of three replicates $( \pm$ SDs). The means denoted with different letters differ significantly at $P<0.05$

accumulation of melatonin in leaves of watermelon plants under cold stress (Fig. 2). Furthermore, exogenous melatonin improved the cold tolerance of $\mathrm{Cl} / \mathrm{Cl}$ plants, while inhibition of melatonin biosynthesis by CPA attenuated pumpkin- or figleaf gourd rootstockinduced cold tolerance (Fig. 4a, b). These results suggest that melatonin has an important role in pumpkin- or figleaf gourd rootstock-induced cold tolerance. It is worth noting that the increased melatonin contents in $\mathrm{Cl} / \mathrm{Cm}$ or $\mathrm{Cl} / \mathrm{Cm}$ leaves were accompanied by greater increases in melatonin contents in pumpkin or figleaf gourd rootstocks, respectively, after exposure to cold stress. Our previous study provided evidence that, as a long-distance signal, melatonin can be transported from roots to shoots via the xylem, subsequently inducing shoot tolerance to cold stress ${ }^{17}$. These data thus suggest that under cold stress, pumpkin- or figleaf gourd rootstock-sourced melatonin may act as a long-distance signal that induces melatonin accumulation and cold tolerance in watermelon leaves.
Melatonin and MeJA function together in a self-amplifying feedback loop in rootstock-induced cold tolerance

Like melatonin, JAs have important roles in regulating plant tolerance to cold stress ${ }^{43}$. Under cold stress, JAs trigger the degradation of JAZ proteins, which releases INDUCER OF CBF EXPRESSION (ICE) from repression and then activates CBF-mediated transcriptional regulatory cascades ${ }^{20}$. In the current study, we observed that pumpkin and figleaf gourd rootstocks led to increased MeJA accumulation but decreased ClJAZ1 transcript levels in leaves of watermelon plants under cold stress (Fig. 3a). Moreover, exogenous MeJA improved the cold tolerance of $\mathrm{Cl} / \mathrm{Cl}$ plants (Fig. 5a), while inhibition of JA biosynthesis by DIECA decreased the cold tolerance of $\mathrm{Cl} / \mathrm{Cm}$ and $\mathrm{Cl} / \mathrm{Cf}$ plants (Fig. 5b), suggesting that MeJA is involved in rootstock-induced cold tolerance.

Recently, crosstalk between melatonin and MeJA in plant defense against biotic stress has been revealed in some studies. For instance, Liu et al. ${ }^{44}$ revealed that melatonin induces tomato fruit resistance to Botrytis cinerea by 
activating the JA signaling pathway. However, the crosstalk between melatonin and MeJA in abiotic stress responses remains largely unknown. Our results showed that melatonin and MeJA increased the accumulation of each other in the leaves of $\mathrm{Cl} / \mathrm{Cl}$ plants under cold stress (Figs. 4c and 6a), while pretreatment with CPA or DIECA attenuated the pumpkin- or figleaf gourd rootstock-induced increase in MeJA or melatonin, respectively (Figs. 4e and 6b). Furthermore, melatonin- and MeJA-induced cold tolerance was attenuated or completely blocked by DIECA and CPA, respectively, in $\mathrm{Cl} / \mathrm{Cl}$ plants (Figs. 5c and 6c). Taken together, these results suggest that melatonin and MeJA function together in a self-amplifying feedback loop, in which melatonin induces MeJA accumulation and MeJA subsequently increases melatonin accumulation during the cold response of $\mathrm{Cl} / \mathrm{Cm}$ and $\mathrm{Cl} / \mathrm{Cf}$ plants. Such crosstalk between melatonin and MeJA during the cold response is similar to that between ABA and $\mathrm{H}_{2} \mathrm{O}_{2}$ in plant responses to heat and oxidative stresses ${ }^{45}$.

\section{MeJA mediates melatonin- and rootstock-induced $\mathrm{H}_{2} \mathrm{O}_{2}$ accumulation and subsequent cold tolerance}

As an important secondary messenger, the $\mathrm{H}_{2} \mathrm{O}_{2}$ generated by $R B O H$ has an essential role in regulating plant tolerance against various abiotic stresses, including cold stress $^{26,46}$. In our study, pumpkin or figleaf gourd as rootstocks increased the accumulation of $\mathrm{H}_{2} \mathrm{O}_{2}$, as well as the levels of $C l R B O H D$ and $C l R B O H F$ transcripts under cold stress (Fig. 3b, c). Additional experiments showed that exogenous application of $\mathrm{H}_{2} \mathrm{O}_{2}$ enhanced the cold tolerance of $\mathrm{Cl} / \mathrm{Cl}$ plants, while inhibition of $\mathrm{H}_{2} \mathrm{O}_{2}$ generation by DPI prevented pumpkin- or figleaf gourd rootstock-induced cold tolerance (Fig. 5a, b). These results indicate that $\mathrm{H}_{2} \mathrm{O}_{2}$ is involved in rootstockinduced cold tolerance, and these findings are consistent with previous findings that $\mathrm{H}_{2} \mathrm{O}_{2}$ is involved in rootstockinduced heat tolerance of cucumber plants ${ }^{5}$.

Melatonin is a well-documented antioxidant that can effectively remove reactive oxygen species (ROS) and consequently alleviate oxidative stress ${ }^{47}$. However, accumulating studies have shown that melatonin can increase $\mathrm{H}_{2} \mathrm{O}_{2}$ accumulation in plant tissues, and as a key signaling molecule, $\mathrm{H}_{2} \mathrm{O}_{2}$ mediates melatonin-induced lateral root formation, stomatal closure, and tolerance to environmental stresses ${ }^{12,48,49}$. In agreement with these findings, our findings also showed that melatonin increased the $\mathrm{H}_{2} \mathrm{O}_{2}$ accumulation in $\mathrm{Cl} / \mathrm{Cl}$ leaves, while pretreatment with CPA completely abolished the pumpkin- or figleaf gourd rootstock-induced increase in $\mathrm{H}_{2} \mathrm{O}_{2}$ under cold stress (Fig. 4d, f). Moreover, DPI pretreatment completely blocked the melatonin-induced cold tolerance of $\mathrm{Cl} / \mathrm{Cl}$ plants (Fig. 5c). Thus, it is apparent that $\mathrm{H}_{2} \mathrm{O}_{2}$ mediates melatonin-induced cold tolerance of $\mathrm{Cl} / \mathrm{Cm}$ and $\mathrm{Cl} / \mathrm{Cf}$ plants.

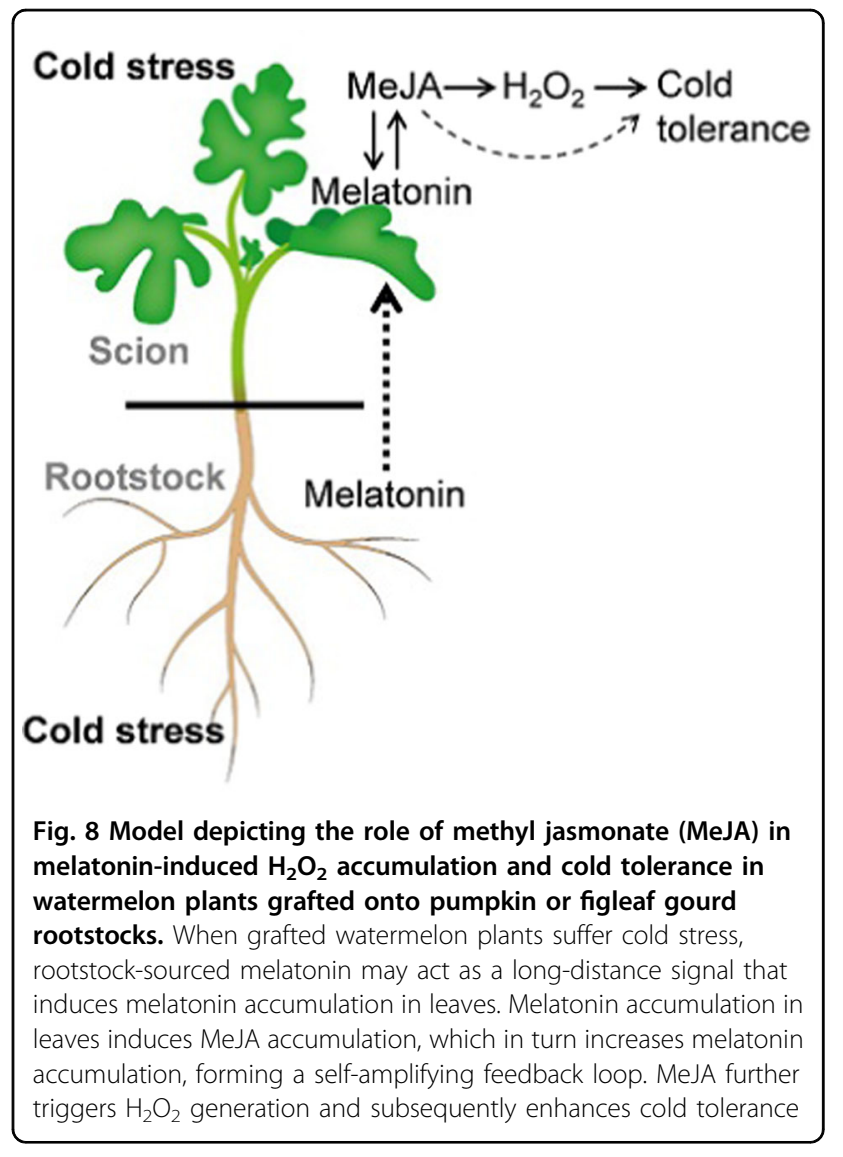

It has been well established that JA and $\mathrm{H}_{2} \mathrm{O}_{2}$ function synergistically to regulate multiple physiological processes, such as leaf senescence, drought tolerance, stomatal closure, and wound-induced responses, and JA functions upstream of $\mathrm{H}_{2} \mathrm{O}_{2}{ }^{50,51}$. Consistent with the data of these studies, our data show that MeJA mediates the melatonin-induced cold tolerance of $\mathrm{Cl} / \mathrm{Cm}$ and $\mathrm{Cl} / \mathrm{Cf}$ plants by inducing $\mathrm{H}_{2} \mathrm{O}_{2}$ accumulation. This conclusion is based on the following evidence: (1) foliar application of MeJA increased $\mathrm{H}_{2} \mathrm{O}_{2}$ accumulation in $\mathrm{Cl} / \mathrm{Cl}$ plants in response to cold (Fig. 7a), while $\mathrm{H}_{2} \mathrm{O}_{2}$ application failed to induce an increase in MeJA accumulation (Supplementary Fig. S2); (2) pretreatment with DIECA prevented melatonin- or rootstock-induced $\mathrm{H}_{2} \mathrm{O}_{2}$ accumulation (Fig. 7a, b); and (3) application of DPI attenuated the MeJAinduced cold tolerance of $\mathrm{Cl} / \mathrm{Cl}$ plants (Fig. 7c).

To date, the mechanisms underlying rootstock-induced shoot tolerance to cold stress are unclear; however, we have demonstrated in the present study that, as a potential rootto-shoot signal, melatonin is involved in rootstock-induced cold tolerance. The rootstock-promoted melatonin accumulation in leaves induces MeJA accumulation, which in turn increases melatonin accumulation, forming a selfamplifying feedback loop. MeJA further triggers $\mathrm{H}_{2} \mathrm{O}_{2}$ generation and subsequently enhances cold tolerance (Fig. 8). 
Thus, melatonin-induced increases in MeJA and subsequent $\mathrm{H}_{2} \mathrm{O}_{2}$ have an essential role in rootstock-scion communication in response to cold stress.

\section{Acknowledgements}

This work was supported by the National Key Research and Development Program of China (2018YFD1000800), the National Natural Science Foundation of China (31801884, 31972479), the Earmarked Fund for Modern Agroindustry Technology Research System of China (CARS-25), and the Tang Scholar of Northwest A\&F University.

\section{Author details}

${ }^{1}$ State Key Laboratory of Crop Stress Biology for Arid Areas, College of Horticulture, Northwest A\&F University, 712100 Yangling, Shaanxi, China. ${ }^{2}$ College of Horticulture and Plant Protection, Henan University of Science and Technology, 471023 Luoyang, Henan, China. ${ }^{3}$ State Key Laboratory of Vegetable Germplasm Innovation, 300384 Tianjin, China

\section{Author contributions}

H.L. and X.Z. planned and designed the research; H.L., Y.G., Z.L., K.X., J.C., J.M. and C.W. performed the experiments and analyzed the data; and H.L., G.A., and X.Z. wrote the manuscript. H.L. and Y.G. contributed equally to this work.

\section{Conflict of interest}

The authors declare no competing interests.

Supplementary information The online version contains supplementary material available at https://doi.org/10.1038/s41438-021-00496-0.

Received: 18 August 2020 Revised: 9 January 2021 Accepted: 14 January 2021

Published online: 10 March 2021

\section{References}

1. Rahman, A. Auxin: a regulator of cold stress response. Physiol. Plant. 147 28-35 (2013)

2. Guo, X. Y., Liu, D. F. \& Chong, K. Cold signaling in plants: Insights into mechanisms and regulation. J. Int. Plant Biol. 60, 745-756 (2018).

3. Wilkinson, S. \& Davies, W. J. Drought, ozone, ABA and ethylene: new insights from cell to plant to community. Plant Cell Environ. 33, 510-525 (2010).

4. Zhou, Y. H. et al. Chill-induced decrease in capacity of RuBP carboxylation and associated $\mathrm{H}_{2} \mathrm{O}_{2}$ accumulation in cucumber leaves are alleviated by grafting onto figleaf gourd. Ann. Bot. 100, 839-848 (2007).

5. Li, H. et al. Hydrogen peroxide mediates abscisic acid-induced HSP70 accumulation and heat tolerance in grafted cucumber plants. Plant Cell Environ. 37, 2768-2780 (2014).

6. Calvo, J. R., González-Yanes, C. \& Maldonado, M. D. The role of melatonin in the cells of the innate immunity: a review. J. Pineal Res. 55, 103-120 (2013).

7. Dubbels, R. et al. Melatonin in edible plants identified by radioimmunoassay and by high performance liquid chromatography-mass spectrometry. J. Pineal Res. 18, 28-31 (1995).

8. Hattori, A. et al. Identification of melatonin in plants and its effects on plasma melatonin levels and binding to melatonin receptors in vertebrates. Biochem. Mol. Biol. Int. 35, 627-634 (1995).

9. Arnao, M. B. \& Hernández-Ruiz, J. Melatonin: plant growth regulator and/or biostimulator during stress? Trends Plant Sci. 19, 789-797 (2014)

10. Li, H. et al. Alkanes (C29 and C31)-mediated intracuticular wax accumulation contributes to melatonin- and ABA-induced drought tolerance in watermelon. J. Plant Growth Regul. https://doi.org/10.1007/s00344-020-10099-z (2020).

11. Sun, Y. D. et al. Melatonin treatment improves the shelf-life and postharvest quality of table grape (Vitis labrusca L. cv. 'Fengzao'). J. Berry Res. https://doi.org/ 10.3233/JBR-200569 (2020).

12. Wei, J. et al. Phytomelatonin receptor PMTR1-mediated signaling regulates stomatal closure in Arabidopsis thaliana. J. Pineal Res. 65, e12500 (2018).

13. Arnao, M. B. \& Hernández-Ruiz, J. Melatonin: a new plant hormone and/or a plant master regulator? Trends Plant Sci. 24, 38-48 (2018).
14. Bose, S. K. \& Howlader, P. Melatonin plays multifunctional role in horticultural crops against environmental stresses: a review. Environ. Exp. Bot. 176, 104063 (2020).

15. Tan, D. X. et al. Novel rhythms of N1-acetyl-N2-formyl-5-methoxykynuramine and its precursor melatonin in water hyacinth: importance for phytoremediation. FASEB J. 21, 1724-1729 (2007).

16. Mukherjee, S. et al. Salt stress-induced seedling growth inhibition coincides with differential distribution of serotonin and melatonin in sunflower seedling roots and cotyledons. Physiol. Plant. 152, 714-728 (2014).

17. Li, H. et al. Local melatonin application induces cold tolerance in distant organs of Citrullus lanatus L. via long distance transport. Sci. Rep. 8, 40858 (2017).

18. Huang, $\mathrm{H}$. et al. Jasmonate action in plant growth and development. J. Exp. Bot. 68, 1349-1359 (2017).

19. Yu, X. X. et al. The roles of methyl jasmonate to stress in plants. Funct. Plant Biol. 46, 197-212 (2019).

20. $\mathrm{Hu}$, Y. et al. Jasmonate regulates the INDUCER OF CBF EXPRESSION-C-REPEAT BINDING FACTOR/DRE BINDING FACTOR1 cascade and freezing tolerance in Arabidopsis. Plant Cell. 25, 2907-2924 (2013).

21. Wang, $G$. et al. Systemic root-shoot signaling drives jasmonate-based root defense against nematodes. Curr. Biol. 29, 3430-3438 (2019).

22. Schulze, A. et al. Wound-induced shoot-to-root relocation of JA-lle precursors coordinates Arabidopsis growth. Mol. Plant. 12, 1383-1394 (2019).

23. Rivero, R. M. et al. Resistance to cold and heat stress: accumulation of phenolic compounds in tomato and watermelon plants. Plant Sci. 160, 315-321 (2001).

24. Liu, H. Y. et al. Study on relationship between physiological changes and chilling tolerance in grafted watermelon seedlings under low temperature stress. Agric. Sin. Chin. 36, 1325-1329 (2003).

25. Shi, X. F. et al. iTRAQ-based quantitative proteomics analysis of cold stressinduced mechanisms in grafted watermelon seedlings. J. Proteom. 192 311-320 (2019).

26. Zhu, J. K. Abiotic stress signaling and responses in plants. Cell 167, 313-324 (2016).

27. Davis, A. R. et al. Cucurbit grafting. Crit. Rev. Plant Sci. 27, 50-74 (2008).

28. Wen, D. et al. Promoting roles of melatonin in adventitious root development of Solanumly copersicum L. by regulating auxin and nitric oxide signaling. Front. Plant Sci. 7, 718 (2016).

29. Park, W. J. Melatonin as an endogenous plant regulatory signal: debates and perspectives. J. Plant Biol. 54, 143-149 (2011).

30. Rajendran, S. K. et al. Differential activation of sporamin expression in response to abiotic mechanical wounding and biotic herbivore attack in the sweet potato. BMC Plant Biol. 14, 112 (2014)

31. Xia, X. J. et al. Reactive oxygen species are involved in brassinosteroid-induced stress tolerance in cucumber. Plant Physiol. 150, 801-814 (2009).

32. Hong, S. W., Lee, U. \& Vierling, E. Arabidopsis hot mutants define multiple functions required for acclimation to high temperatures. Plant Physiol. 132, 757-767 (2003).

33. Okazaki, M. \& Ezura, H. Profiling of melatonin in the model tomato (Solanum lycopersicum L.) cultivar Micro-Tom. J. Pineal Res. 46, 338-343 (2009).

34. Pan, X., Welti, R. \& Wang, X. Quantitative analysis of major plant hormones in crude plant extracts by high-performance liquid chromatography-mass spectrometry. Nat. Protoc. 5, 986-992 (2010).

35. Bellincampi, D. et al. Extracellular $\mathrm{H}_{2} \mathrm{O}_{2}$ induced by oligogalacturonides is not involved in the inhibition of the auxin-regulated rolB gene expression in tobacco leaf explants. Plant Physiol. 122, 1379-1385 (2000).

36. Thordal-Christensen, $\mathrm{H}$. et al. Subcellular localization of $\mathrm{H}_{2} \mathrm{O}_{2}$ in plants. $\mathrm{H}_{2} \mathrm{O}_{2}$ accumulation in papillae and hypersensitive response during the barleypowdery mildew interaction. Plant J. 11, 1187-1194 (1997).

37. Kong, Q. S. et al. Identification of suitable reference genes for gene expression normalization in GRT-PCR analysis in watermelon. PLOS ONE 9, e90612 (2014).

38. Livak, K. J. \& Schmittgen, T. D. Analysis of relative gene expression data using real-time quantitative $P C R$ and the $2^{-\Delta C T}$ method. Methods 25, 402-408 (2001).

39. $\mathrm{Xu}, \mathrm{J} . \mathrm{H}$. et al. Comparative transcriptome profiling of chilling stress responsiveness in grafted watermelon seedlings. Plant Physiol. Biochem. 109, 561-570 (2016).

40. Liu, J. Y., Shi, Y. T. \& Yang, S. H. Insights into the regulation of C-repeat binding factors in plant cold signaling. J. Int. Plant Biol. 60, 780-795 (2018).

41. Shi, $\mathrm{H}$. et al. Melatonin induces the transcripts of CBF/DREB1s and their involvement in both abiotic and biotic stresses in Arabidopsis. J. Pineal Res. 59 334-342 (2015). 
42. Zhang, N. et al. Roles of melatonin in abiotic stress resistance in plants. J. Exp. Bot. 66, 647-656 (2015).

43. Kazan, K. Diverse roles of jasmonates and ethylene in abiotic stress tolerance. Trends Plant Sci. 20, 219-229 (2015).

44. Liu, C. X. et al. Melatonin induces disease resistance to Botrytis cinerea in tomato fruit by activating jasmonic acid signaling pathway. J. Agric. Food Chem. 67, 6116-6124 (2019).

45. Zhou, J. et al. $\mathrm{H}_{2} \mathrm{O}_{2}$ mediates the crosstalk of brassinosteroid and abscisic acid in tomato responses to heat and oxidative stresses. J. Exp. Bot. 65, 4371-4383 (2014).

46. Ahammed, G. J. et al. Tomato WRKY81 acts as a negative regulator for drought tolerance by modulating guard cell $\mathrm{H}_{2} \mathrm{O}_{2}$-mediated stomatal closure. Environ. Exp. Bot. 171, 103960 (2020).
47. Zhang, H. M. \& Zhang, Y. Q. Melatonin: a well-documented antioxidant with conditional pro-oxidant actions. J. Pineal Res. 57, 131-146 (2014).

48. Gong, B. et al. Hydrogen peroxide produced by NADPH oxidase: a novel downstream signaling pathway in melatonin-induced stress tolerance in Solanum lycopersicum. Physiol. Plant. 160, 396-409 (2017).

49. Chen, Z . et al. Hydrogen peroxide acts downstream of melatonin to induce lateral root formation. Ann. Bot. 121, 1127-1136 (2018).

50. Suhita, D. et al. Cytoplasmic alkalization precedes reactive oxygen species production during methyl jasmonate-and abscisic acid-induced stomatal closure. Plant Physiol. 134, 1536-1545 (2004).

51. Nazir, F., Fariduddin, Q. \& Khan, T. A. Hydrogen peroxide as a signalling molecule in plants and its crosstalk with other plant growth regulators under heavy metal stress. Chemosphere 252, 126486 (2020). 